УДК 629.7.002.72:621.454.3

Шилина Е. В. ${ }^{1}$, Шилин С. А. ${ }^{1}$, Артеменко В. А. ${ }^{1}$, Коваленко В. А. ${ }^{1}$, Санин А. Ф. ${ }^{2}$

${ }^{1}$ Государственное предприятие «Конструкторское бюро "Южное"» им. М. К. Янгеля. Украина, г. Днепр 2 Днипровский национальный университет им. О. Гончара, Украина, г. Днипро

\title{
РАЗРАБОТКА КОМПЛЕКСА СРЕДСТВ ТЕХНОЛОГИЧЕСКОГО ОСНАЩЕНИЯ, ОБЕСПЕЧИВАЮЩЕГО ПОЛНЫЙ ЦИКЛ ИЗГОТОВЛЕНИЯ КОРПУСА РДТТ С ЗАДАННЫМИ ГЕОМЕТРИЧЕСКИМИ ПАРАМЕТРАМИ
}

В статье рассмотрен вариант технологического оснащения для изготовления корпусов РДТТ методом «мокрой» намотки в условиях мелкосерийного производства. Это оснащение разрабатывалось на основании многолетнего опыта изготовления таких конструкций и является оптимальным исходя из трудозатрат и обеспечения высоких требований, предбявляемых к данным конструкииям. Наибольшее внимания в статье уделено технологическим аспектам эксплуатации разработанной оснастки. [dx.doi.org/10.29010/082.5]

Ключевые слова: корпус типа «кокон»; средства технологического оснащения; металлическая разборная оправка.

\section{Введение}

Изготовление корпусов типа «кокон» в настоящее время осуществляется в основном методом «мокрой» намотки из высокопрочного углеродного волокна и связующего эпоксидного типа на пятикоординатном намоточном станке с числовым программным управлением. 
Важнейшей задачей при подготовке мелкосерийного производства таких конструкций является проектирование и изготовление технологической оснастки, которая позволит обеспечить необходимые показатели качества производимых изделий при минимальных финансовых затратах.

В настоящее время известен широкий спектр оправок для изготовления конструкций такого типа. Наиболее распространены: надувные, цельнометаллические, разрушаемые, металлические разборные оправки.

Результаты анализа литературных источников [1-4, 6-10] показывают, что для условий мелкосерийного и серийного производства оптимальным по трудозатратам и обеспечению заданных геометрических параметров является использование металлической разборной оправки.

Недостатками применения других типов оправок являются:

- надувная оправка - достаточно сложно обеспечить точную фиксацию закладных элементов и стабильные выходные геометрические параметры корпуса;

- цельнометаллическая оправка - одноразовое применение и увеличение массы конструкции корпуса;

- разрушаемая оправка - трудоемкий процесс изготовления и ограниченный срок ее хранения.

Поэтому, на основании этого факта и имеющегося опыта были проведены работы по проектированию и изготовлению металлической разборной оправки и технологической оснастки для эксплуатации такой оправки [11, 12, 5].

Технология изготовления корпуса ракетного двигателя твердого топлива (РДТТ) состоит из следующих основных этапов:

- сборка металлической разборной оправки;

- нанесение внутреннего теплозащитного покрытия (ВТЗП) корпуса;

- намотка силовой оболочки корпуса;

- намотка шпангоутов и оболочки связи корпуса;

- термообработка корпуса;

- механическая обработка корпуса;

- контроль выходных геометрические параметры корпуса;

- неразрушающий контроль качества изготовленного корпуса;

- контроль герметичности корпуса;

- статические испытания корпуса на растяжение, сжатие и внутреннее давление;

- контроль выходных геометрических параметров корпуса;

- неразрушающие методы контроля качества материалов корпуса;

- контроль герметичности корпуса.

Комплекс средств технологического оснащения состоит из следующих элементов: металлическая разборная оправка; стапель сборки оправки, стапель разборки оправки, стапель слесарный, кондукторы для сверления отверстий и вклейки закладных элементов.

Наибольшее внимание в проектировании средств технологического оснащения уделено оправке т.к. она задействуется во всех ключевых этапах изготовления.

К оправке предъявляются требования такие как:

- возможность извлечения элементов оправки через заднее полюсное отверстие корпуса;

- обеспечение стабильных выходных геометрических параметров при многоразовой сборке-разборке ее элементов (до 100 циклов);

- обеспечение прочности составных элементов при цикличной знакопеременной нагрузке (при намотке на намоточном станке и термообработке) и температурном воздействии до $150{ }^{\circ} \mathrm{C}$;

- возможность формования шпангоутов за единый технологический процесс изготовления корпуса.

В результате разработана и изготовлена оправка, конечный вид которой представляет собой конструкцию многоразового применения, на вал которой крепятся формообразующие секции (карты) (рисунки 1, 2).

Основным элементом оправки является полый вал-основа, имеющий специально обработанные посадочные поверхности, на которые базируются формообразующие карты (замыкающие и выпадающие). Количество и форма карт выбираются исходя из величины диаметра отверстия в большем фланце.

Карты крепятся изнутри вала при помощи специальных фиксирующих болтов. Такая конструкция обеспечивает создание формообразующей поверхности для укладки на ней ВТЗП и последующей намотки и механической обработки силовой оболочки корпуса РДТТ.

Технология сборки и разборки оправки. Процесс сборки оправки состоит из следующих основных этапов:

- установка вала на стапель сборки;

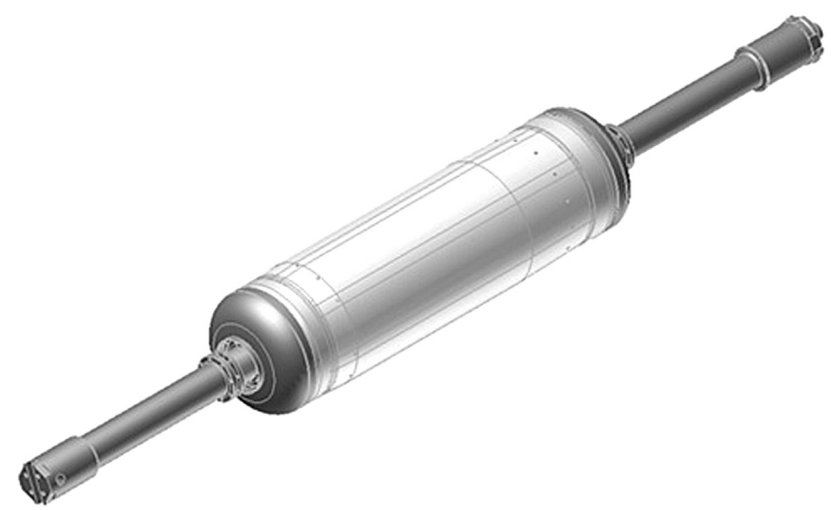

Рис. 1. Общий вид металлической разборной оправки в сборе 


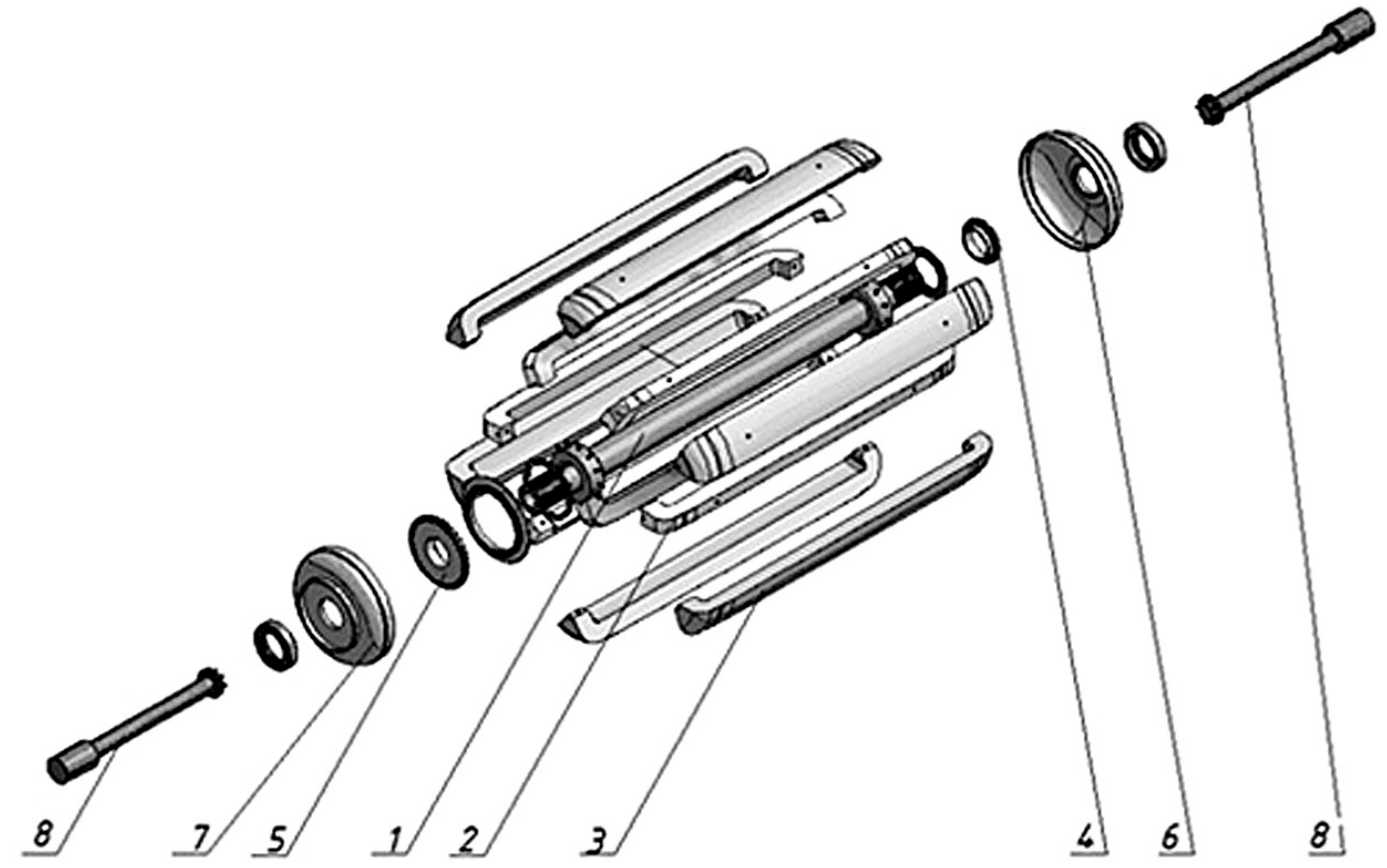

Рис. 2. Конструктивная схема металлической разборной оправки:

1 - сплошной вал; 2, 3- выпадающие и замыкающие карты; 4, 5 - передний и задний фланцедержатели;

6,7 - переднее и заднее ложные днища; 8 - передняя и задняя цапфы

- установка и закрепление замыкающих и выпадающих карт;

- установка и закрепление фланцедержателей с штатными фланцами передним и задним;

- установка и закрепление цапф для намотки корпуса РДТТ;

- установка и закрепление ложных днищ оправки.

Данные этапы не связаны последовательно между собой, между ними проводятся промежуточные и основные операции изготовления корпуса такие как установка фланцев с нанесенным ВТЗП, нанесение ВТЗП цилиндрической части корпуса, намотка силовой оболочки корпуса.

Схематично процесс сборки выглядит следующим образом:

1. Установка центрального вала на стапель сборки и монтаж механизма вращения (рисунок 3 ).

2. Монтаж и фиксация карт по посадочным местам на валу (рисунок 4). Подгонка собранной поверхности.

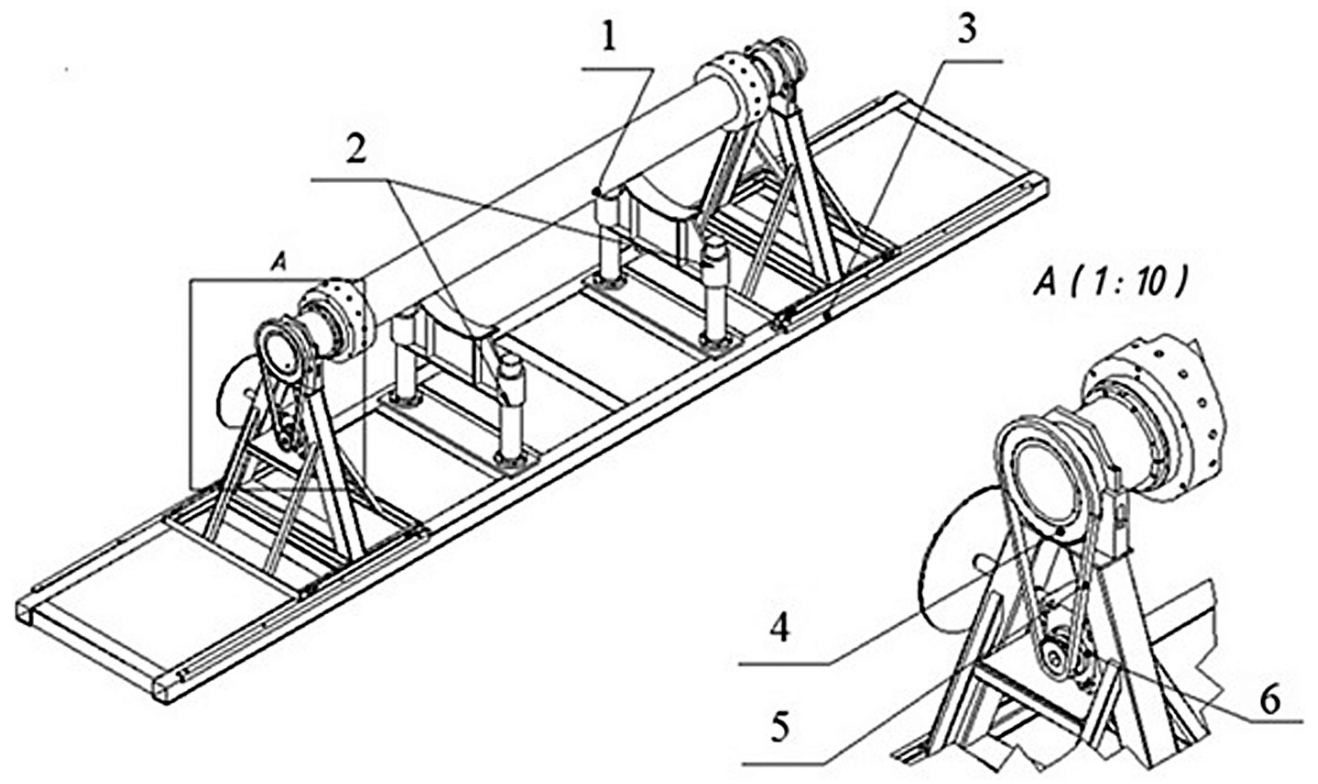

Рис. 3. Стыковка вала с редуктором:

1 - вал; 2 - ползун; 3 - рама стапеля; 4 - звездочка; 5 - цепь; 6 - редуктор 


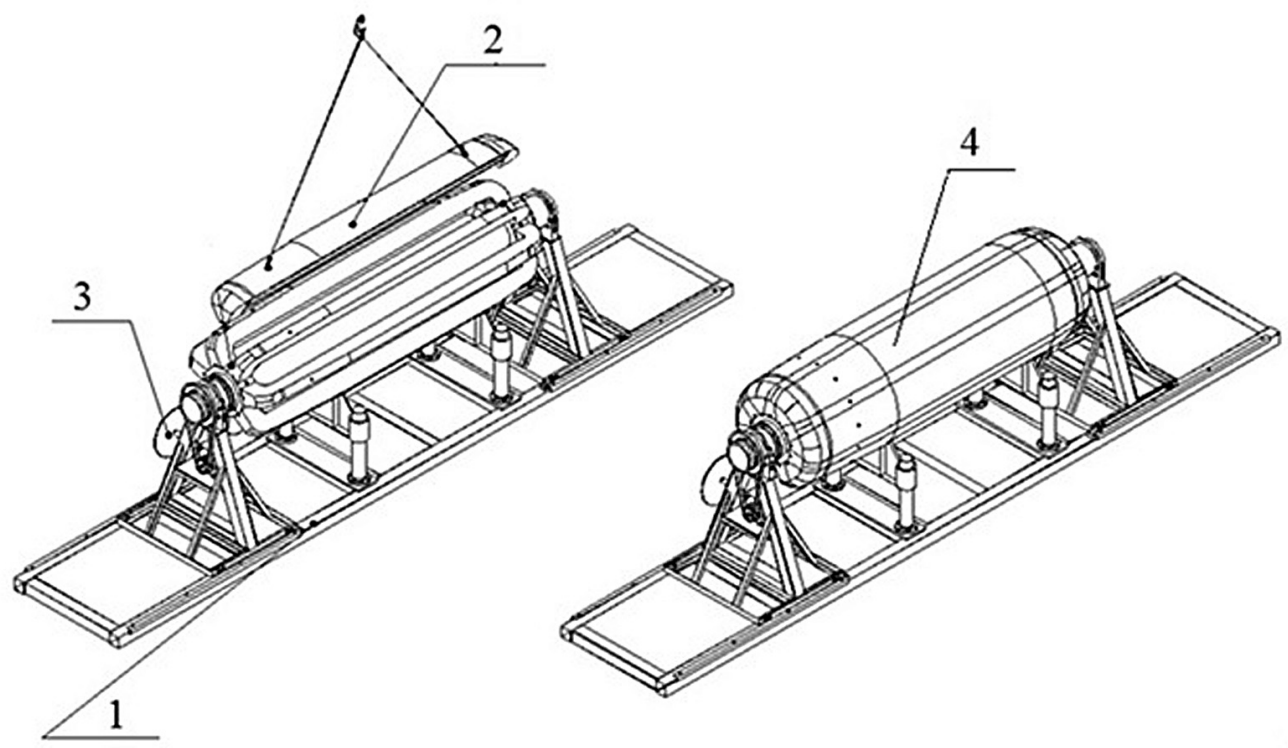

Рис. 4. Монтаж замыкающих карт на валу:

1 - стапель сборки; 2 - карта замыкающая; 3 - маховик; 4 - оправка в сборе

Монтаж карт осуществляется поэтапно - сначала устанавливаются все выпадающие, а затем все замыкающие карты, это вызвано геометрическими особенностями карт.

После выполнения монтажа проводится обмер профиля собранной оправки на соответствие требованиям конструкторской документации.

3. Нанесение чехла цилиндрической части защитно-крепящего слоя. Чехол цилиндрической час- ти защитно-крепящего слоя наносится на оправку вручную на стапеле сборки. Доступ к торцам оправки осуществляется ее поднятием на гидравлических домкратах. Далее чехол защитно-крепящего слоя цилиндрической части сшивается с чехлами днищ с ВТЗП (не является сборочной операцией).

4. Сборка фланцедержателей с фланцами, на которые нанесено ВТЗП днищ (рисунок 5). Установка фланцедержателей в сборе с фланцами на оправ-
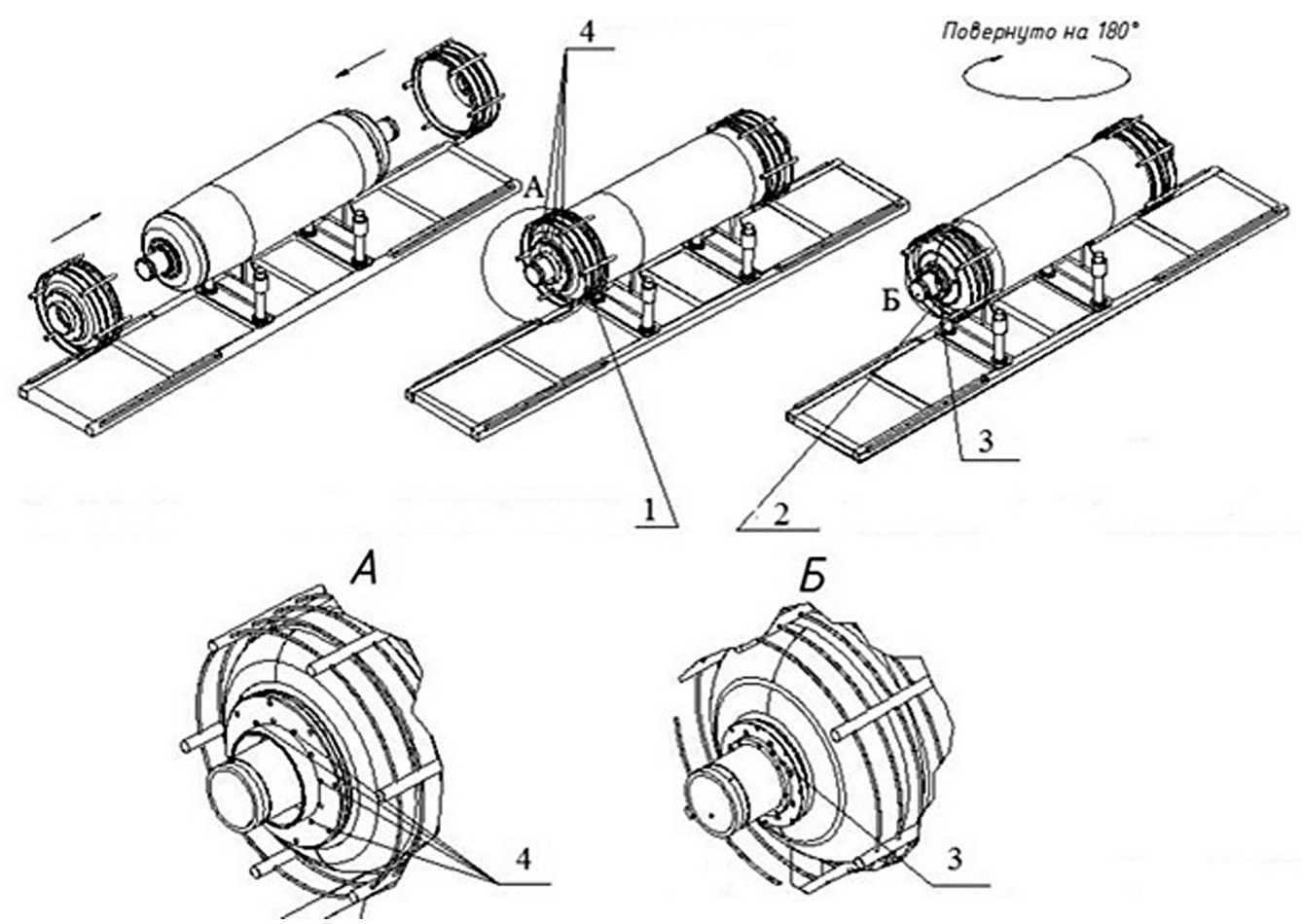

Рис. 5. Установка ВТЗП днищ:

1 - корзина с ВТЗП переднего днища; 2 - корзина с ВТЗП заднего днища; 3 - фланцедержатель; 4 - крепежные винты 


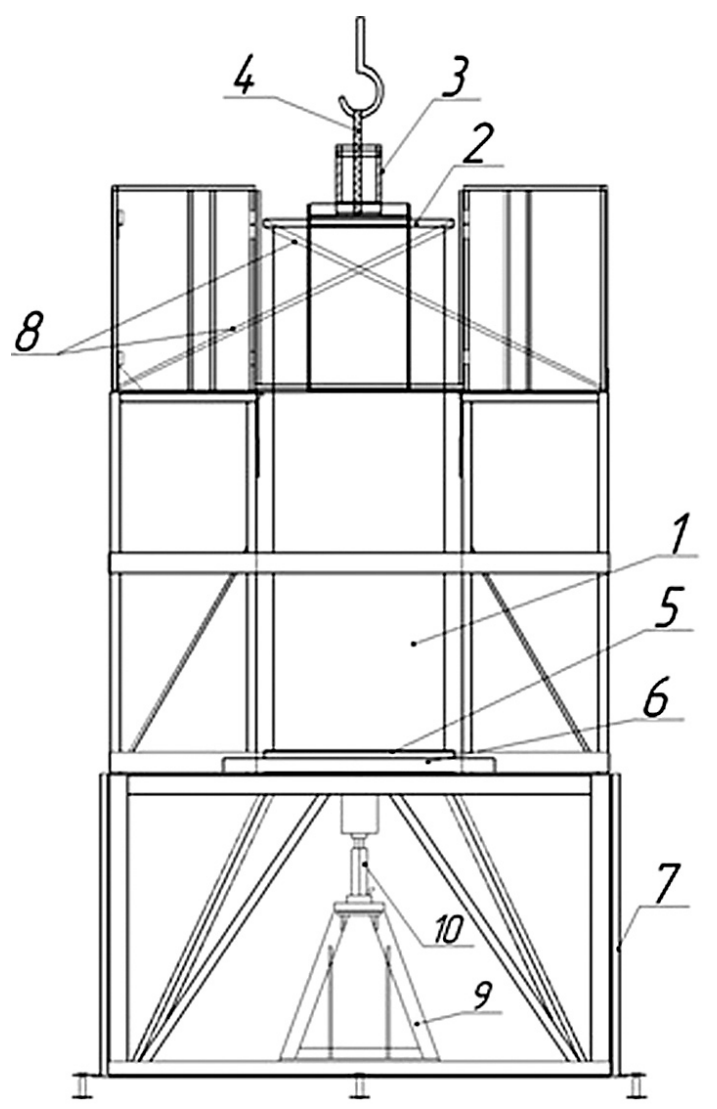

Рис. 6. Схема установки оправки с заготовкой корпуса на стапель разборки:

1 - заготовка корпуса; 2 - бандаж задний; 3 - вал; 4 - строп; 5 - бандаж передний; 6 - плита; 7 - стапель разборки; 8 - стропы страховочные; 9 - стойка; 10 - домкрат

ку по направляющим штифтам и пазам, обеспечивая закрутку штатных фланцев между собой по оси.

5. Формование ВТЗП цилиндрической части путем укладки слоев невулканизированной резины (не является сборочной операцией)

6. Автоматизированная намотка силовой оболочки корпуса РДТТ на намоточном станке с числовым программным управлением по управляющим программам (не является сборочной операцией).

7. Установка ложных днищ: на стапеле сборки для формования шпангоутов с силовой оболочкой корпуса. Установка ложных днищ производится на фланцедержатели с помощью крепежных элементов. Перед установкой на оправку, рабочую поверхность ложных днищ покрывают разделительным слоем;

После отверждения заготовки корпуса выполняют работы по извлечению оправки. Технология разборки оправки осуществляется в несколько этапов:

- черновая подрезка шпангоутов и демонтаж ложных днищ;

- демонтаж фланцедержателей;

- извлечение вала;

- извлечение выпадающих карт;

- извлечение замыкающих карт.
Все операции по извлечению оправки, кроме демонтажа ложных днищ, проводят в вертикальном положении на специально разработанном стапеле разборки при помощи специально разработанных приспособлений. Для предотвращения выпадения карт в вертикальном положении их фиксируют между собой при помощи фиксирующего кольца.

На первом этапе извлекают вал, выкручивают винты фиксирующие карты, а затем при помощи гидравлического домкрата и крана производят его распрессовку. Далее на передний и задний фланец монтируют специально спроектированные приспособления, которые позволяют привести в горизонтальное плоскопараллельное движение карты в сторону оси корпуса, затем при помощи крана извлекают карту. Извлечение карт осуществляется поочередно - сначала извлекаются все выпадающие карты, а затем все замыкающие.

\section{Выводы}

1. Спроектированная и изготовленная металлическая разборная оправка для изготовления корпусов РДТТ методом «мокрой» намотки, разработанная технология сборки и разборки оправки обеспечивают полный цикл изготовления корпуса.

2. Разработанная конструкция разборной оправки, ее технология сборки и разборки, обеспечивают повышение стабильности геометрических параметров изготавливаемых с помощью оправки корпусов двигателей.

3. Снижение энерго и трудозатрат изготовления корпуса РДТТ обеспечивается за счет многоразового использования металлической разборной оправки.

\section{Литература}

[1] Буланов И.М., Воробей В.В. Технология ракетных и аэрокосмических конструкций из композиционных материалов [Текст]: учеб. для вузов / И.М. Буланов, В.В. Воробей. - М.: Изд-во МГТУ им. Н.Э. Баулана, 1998 г. -516 c.

[2] Пат. 1004134 CССР М.Кл3 В 29 D 23/12. Оправка для изготовления изделий методом намотки [Текст] / И.А. Кожевин, С.А. Хомяков, Р.Г. Залялетдинов (СССР). - № 3337918/23-05; заявл. 03.09.81; опубл. 15.03.83, Бюл. № 10. -3 с.: ил.

[3] Комков М.А. Технология изготовления композитных торовых баллонов для дыхательных аппаратов в условиях серийного производства [Текст] / М.А. Комков // Известия высших учебных заведений. Машиностроение. - М., 2006. - № 12 - С. 47-56

[4] Пат. 2504471 Российская Федерация, МПК В29С 53/82. Разборная оправка [Текст] / Д.А. Лаптев, Д.А. Попова; заявитель и патентообладатель ООО «Пермский завод «Машиностроитель». - 
№ 2012130738/05; заявл. 17.07.12; опубл. 20.01.14, Бюл. № 2. - 10 с.: ил

[5] Пат. Украины, МПК В29C 53/82. Разборная оправка для изготовления высокопрочных оболочек из композиционных материалов [Текст] / А.М. Потапов, В.А. Коваленко, Е.В. Шилина, С.А. Шилин, А.И. Мищенко, С.В. Федоренко, А.А. Малахов; патентообадатель ГП «КБ «Южное». - № 106192; заявл. 10.08.15; опубл. 25.04.16, Бюл. № 8. -3 с.: ил.

[6] Санин Ф.П., Кучма Л.Д., Джур Е.А, Санин А.Ф. Твердотопливные ракетные двигатели. Материалы и технологии [Текст] : учеб. пособие / Ф.П. Санин, Л.Д. Кучма, Е.А. Джур, А.Ф. Санин. - Днепропетровск: Изд-во Днепропетр. ун-та, 1999. - 320 с.

[7] Пат. 478740 СССР М.Кл В 29d 23/12. Оправка для изготовления стеклопластиковых изделий намоткой [Текст] /Г.Ф. Северов, А.И. Зайцев, А.М. Чвикалов, В.А. Кузьмин (СССР). - № 1778224/23-5; заявл. 27.04.72; опубл. 30.07.75, Бюл. № 28. -2 с.: ил.

[8] Справочник по композиционным материалам: В 2-х кн. Кн. 2 [Текст] / под ред. Дж. Любина; пер. с англ. А.Б. Геллера и др.; под ред. Б.Э. Геллера - М.: Машиностроение, 1988. - 584 с.

[9] Шайдурова Г.И. Особенности разработки средств технологического оснащения для производства из- делий из полимерно-композиционных материалов методом намотки [Текст] / Г.И. Шайдурова А.С. Зуев, А.Ю. Ешашев, В.Е. Антипин // Вестник ПНИПУ. Аэрокосмическая техника. - Пермь: ПНИПУ, 2014. - № 36. - C. 64-76.

[10] Пат. № 2507069 Российская Федерация, МПК В29С 53/82. Оправка для изготовления крупногабаритных корпусов из полимерных композиционных материалов [Текст] / Шайдурова Г.И., Шатров В.Б., Лобковский С.А., Рябинин С.Б., Радионов М.В. ; патентообладатель ОАО «НПО «Искра». -№ 2507069, заявл. 15.08.12; опубл. 20.02.2014. Бюл. № 5. - 6 с.: ил.

[11] Шилина Е.В. Формообразующие оправки для изготовления корпусов РДТТ из полимерных композиционных материалов методом «мокрой» намотки (обзор) [Текст] / Е.В. Шилина // XVIII Международная молодежная научно-практическая конференция «Человек и космос»: Сборник тезисов. Днепропетровск - 2016. - с. 400

[12] Шилина Е.В. Создание технологического оснащения для изготовления корпусов типа «кокон» [Текст] / Е.В. Шилина, С.А. Шилин, А.М. Потапов, А.Ф. Санин // Вісник Дніпропетровського університету. Серія: ракетно-космічна техніка. Том 1, выпуск $19-2015$. - с. 186-191.

Shylina K. V. ${ }^{1}$, Shylin S. A. ${ }^{1}$, Artemenko V. A. ${ }^{1}$, Kovalenko V. A. ${ }^{1}$, Sanin A. F. ${ }^{2}$

${ }^{1}$ Yuzhnoye, State-owned Design Office named after M. K. Yangel. Ukraine, Dnipro

${ }^{2}$ Oles Gonchar Dnipro National University. Ukraine, Dnipro

\section{DEVELOPMENT OF EQUIPMENT SET, WHICH PROVIDES A COMPLETE CYCLE OF SOLID PROPELLANT ROCKET MOTOR CASE MANUFACTURING WITH SPECIFIED GEOMETRICAL PARAMETERS}

This paper contains, to our opinion, an optimal choice for selection of support equipment for Solid Propellant Rocket Motor (SPRM) cases manufacturing using "wet" winding method in the small-batch manufacturing conditions. This equipment was developed based on long experience in manufacturing of this type of structures and it is optimal in terms of labor content and implementation of high requirements that are specified for these structures. Main attention in this paper is focused on technological aspects for application of the developed equipment. [dx.doi.org/10.29010/082.5]

Keywords: «cocoon» type case; support equipment; sectional metal mandrel.

\section{References}

[1] Bulanov I.M., Vorobey V.V. Tekhnologiya raketnykh i aerokosmicheskikh konstruktsiy iz kompozitsionnykh materialov [Tekst]: ucheb. dlya vuzov / I.M. Bulanov, V.V. Vorobey. - M.: Izd-vo MGTU im. N.E. Baulana, 1998 g. - 516 s.

[2] Pat. 1004134 SSSR M.Kl3 V 29 D 23/12. Opravka dlya izgotovleniya izdeliy metodom namotki [Tekst] / I.A. Kozhevin, S.A. Khomyakov, R.G. Zalyaletdinov (SSSR). - № 3337918/23-05; zayavl. 03.09.81; opubl. 15.03.83, Byul. № 10. 3 s.: il. 
[3] Komkov M.A. Tekhnologiya izgotovleniya kompozitnykh torovykh ballonov dlya dykhatel'nykh apparatov v usloviyakh seriynogo proizvodstva [Tekst] / M.A. Komkov // Izvestiya vysshikh uchebnykh zavedeniy. Mashinostroyeniye. - M., 2006. - № 12 - S. 47-56

[4] Pat. 2504471 Rossiyskaya Federatsiya, MPK V29S 53/82. Razbornaya opravka [Tekst] / D.A. Laptev, D.A. Popova; zayavitel' i patentoobladatel' OOO «Permskiy zavod «Mashinostroitel'». - № 2012130738/05; zayavl. 17.07.12; opubl. 20.01.14, Byul. № 2. -10 s.: il

[5] Pat. Ukrainy, MPK V29S 53/82. Razbornaya opravka dlya izgotovleniya vysokoprochnykh obolochek iz kompozitsionnykh materialov [Tekst] / A.M. Potapov, V.A. Kovalenko, K.V. Shylina, S.A. Shylin, A.I. Mishchenko, S.V. Fedorenko, A.A. Malakhov; patentoobadatel' GP «KB «Yuzhnoye». - № 106192; zayavl. 10.08.15; opubl. 25.04.16, Byul. № 8. 3 s.: il.

[6] Sanin F.P., Kuchma L.D., Dzhur Ye.A, Sanin A.F. Tverdotoplivnyye raketnyye dvigateli. Materialy i tekhnologii [Tekst] : ucheb. posobiye / F.P. Sanin, L.D. Kuchma, Ye.A. Dzhur, A.F. Sanin. - Dnepropetrovsk: Izd-vo Dnepropetr. un-ta, 1999. $-320 \mathrm{~s}$.

[7] Pat. 478740 SSSR M.Kl V 29d 23/12. Opravka dlya izgotovleniya stekloplastikovykh izdeliy namotkoy [Tekst] / G.F. Severov, A.I. Zaytsev, A.M. Chvikalov, V.A. Kuz'min (SSSR). - № 1778224/23-5; zayavl. 27.04.72; opubl. 30.07.75, Byul. № 28. -2 s.: il.

[8] Spravochnik po kompozitsionnym materialam: V 2-kh kn. Kn. 2 [Tekst] / pod red. Dzh. Lyubina; per. s angl. A.B. Gellera i dr.; pod red. B.E. Gellera - M.: Mashinostroyeniye, 1988. - 584 s.

[9] Shaydurova G.I. Osobennosti razrabotki sredstv tekhnologicheskogo osnashcheniya dlya proizvodstva izdeliy iz polimerno-kompozitsionnykh materialov metodom namotki [Tekst] / G.I. Shaydurova A.S. Zuyev, A.YU. Yeshashev, V.Ye. Antipin // Vestnik PNIPU. Aerokosmicheskaya tekhnika. - Perm': PNIPU, 2014. - № 36. - S. 64-76.

[10] Pat. № 2507069 Rossiyskaya Federatsiya, MPK V29S 53/82. Opravka dlya izgotovleniya krupnogabaritnykh korpusov iz polimernykh kompozitsionnykh materialov [Tekst] / Shaydurova G.I., Shatrov V.B., Lobkovskiy S.A., Ryabinin S.B., Radionov M.V. ; patentoobladatel' OAO «NPO «Iskra». - № 2507069, zayavl. 15.08.12; opubl. 20.02.2014. Byul. № 5. 6 s.: il.

[11] Shylina K.V. Formoobrazuyushchiye opravki dlya izgotovleniya korpusov RDTT iz polimernykh kompozitsionnykh materialov metodom «mokroy» namotki (obzor) [Tekst] / K.V. Shylina // XVIII Mezhdunarodnaya molodezhnaya nauchno-prakticheskaya konferentsiya «Chelovek i kosmos»: Sbornik tezisov. Dnepropetrovsk - 2016. - s. 400

[12] Shylina K.V. Sozdaniye tekhnologicheskogo osnashcheniya dlya izgotovleniya korpusov tipa «kokon» [Tekst] / K.V. Shylina, S.A. Shylin, A.M. Potapov, A.F. Sanin // Vhsnik Dnнpropetrovs'kogo unнversitetu. Serнya: raketno-kosmHchna tekhnнka. Tom 1, vypusk $19-2015$. - s. 186-191. 